\title{
Assistência de Enfermagem ao Público Adolescente na Atenção Primária
}

\author{
Nursing Assistance to the Adolescent Public in Primary Care
}

\section{Carla Bianca de Matos Leal ${ }^{1} *$ Alana Oliveira Porto ${ }^{2}$ Clessiane de Brito Barbosa ${ }^{3}$ Talitha Sonally Soares Fernandes ${ }^{4 *}$ Emanuella Soares Fraga Fernandes $5 *$ Tatiana Barreto Pereira Viana $^{6}$}

\begin{abstract}
RESUMO
Este estudo objetivou analisar as ações de enfermagem voltadas para o público adolescente na atenção básica, por meio de uma revisão integrativa de literatura. Foram analisados 9 artigos das bases de dados BDENF, LILACS e MEDLINE, publicados entre os anos 2012 e 2016, na língua portuguesa. Verificou-se que as ações voltadas para este público, na maioria das vezes, resumem-se em acolhimento e escuta do paciente, isso quando este, procura o serviço. É necessária a criação de ações concretas que atendam às necessidades específicas desse grupo, bem como preparo da equipe para lidar com esta população, propiciando vinculo e atenção integral à saúde do adolescente
\end{abstract}

Palavras-chave: Atenção Básica; Saúde Integral do Adolescente; Promoção da Saúde.

\section{ABSTRACT}

This study aimed to analyze the nursing actions aimed at the adolescent public in basic care, through an integrative literature review. We analyzed 9 articles from the databases BDENF, LILACS and MEDLINE, published between the years 2012 and 2016, in the Portuguese language. It was verified that the actions directed to this public, in the majority of the times, are summarized in reception and listening of the patient, that when this looks for the service. It is necessary to create concrete actions that meet the specific needs of this group, as well as prepare the team to deal with this population providing linkage and integral attention to adolescent health.

Keywords: Primary Care; Comprehensive Adolescent Health; Health promotion.

${ }^{1}$ Enfermeira pela Universidade do Estado da Bahia. DEDC, Campus XII. Guanambi (BA), Brasil. Especialização em curso na área de Saúde Pública com ênfase em Saúde da Família pela UNOPAR. E-mail: carlabiancagbi@hotmail.com

2Enfermeira pela Universidade do Estado da Bahia. DEDC, Campus XII. Guanambi (BA), Brasil. Especialização em curso na área de Saúde Pública com ênfase em Saúde da Família pela UNOPAR. E-mail: alana.udi20@hotmail.com

${ }^{3}$ Enfermeira pela Universidade do Estado da Bahia. DEDC, Campus XII. Guanambi- BA, Brasil. Especialização em curso na área de Saúde Pública com ênfase em Saúde da Família pela Universidade Norte do Paraná. E-mail: clessi.brito@hotmail.com

${ }^{4}$ Enfermeira, Especialização em Saúde Pública Ênfase Saúde da Família pela Faculdade de Educação de Bom Despacho, Docente Auxiliar da Universidade do Estado da Bahia, Guanambi (BA), Brasil. E-mail: talithasonally@gmail.com

${ }^{5}$ Enfermeira, Especialização em Saúde pública ênfase em saúde da família pela Faculdade de Educação de Bom Despacho, Professor Auxiliar Nível B da Universidade do Estado da Bahia, Guanambi (BA), Brasil. E-mail: emspereira@uneb.br

${ }^{6}$ Tatiana Barreto Pereira Viana, Enfermeira, Docente e Coordenadora do Curso de Enfermagem do Departamento de Educação, Campus XII da Universidade do Estado da Bahia (UNEB). Mestra em Enfermagem pela Escola de Enfermagem/UFBA. E-mail: tviana@uneb.br 


\section{ARTIGO ORIGINAL}

\section{INTRODUÇÃO}

Ao longo da história, o sistema de saúde brasileiro sofreu diversas transformações advindas de influencias sociais, econômicas e políticas que ocorreram principalmente no decorrer do século XX. Desse modo, o modelo de atenção curativo e hospitalocêntrico pautado no conceito de saúde como ausência de doença, cedeu lugar a um novo modelo subsidiado a partir da concretização do Sistema Único de Saúde. ${ }^{1}$

Nesse cenário, surge um novo conceito de proteção social abrangente e igualitário com a priorização da assistência à saúde no âmbito da Atenção básica. Este nível de atenção é considerado como a principal porta de entrada do Sistema Único de Saúde e ponto central de comunicação com toda a rede de atenção e por isso deve ser orientada principalmente pelos princípios da integralidade, equidade, universalidade, vínculo e continuidade do cuidado. ${ }^{2,1,3}$

Partindo destes princípios e tendo em vista que a atenção básica desempenha um papel central em assegurar à população em todos os ciclos de vida, um acesso de qualidade aos serviços de saúde, espera-se que a mesma disponha de diversas ações e programas que atendam a todos os públicos mulheres, homens, idosos, crianças e adolescentes - bem como suas necessidades. ${ }^{1}$

No entanto, percebe-se que as ações desenvolvidas na atenção básica voltadas para o público adolescente são insatisfatórias e inconsistentes, principalmente no que diz respeito à prevenção de riscos. Logo, a ausência do adolescente na atenção básica deriva da procura limitada aos serviços, que está estreitamente associada com a falta de vínculo com os profissionais de saúde. ${ }^{4}$

Portanto, é fundamental que as ações da atenção básica voltadas a este público não sejam transitórias e pontuais, mas que englobem a realidade que os mesmos estão inseridos. Para isso faz-se necessário a intersetorialidade e articulação de redes, bem como a disposição dos profissionais de saúde para a busca e conservação dos adolescentes nos serviços, promovendo vínculo e continuidade. $^{5}$

Partindo deste pressuposto destaca-se a importância do profissional enfermeiro para o atendimento destes adolescentes, pois o mesmo se configura como um articulador das diversas ações realizadas na atenção básica e principal responsável pela população adscrita e pelos cuidados a ela prestados, mesmo em outros pontos da rede de atenção. ${ }^{1}$ Assim, a partir das inquietações sobre a temática, o presente estudo tem como objetivoanalisar nas publicações cientificas quais as ações de enfermagem voltadas especificamente para o público adolescente no âmbito da atenção básica.

\section{METODOLOGIA}

Este estudo trata-se de uma revisão integrativa - que segundo Soares et al. (2014) é "um tipo de revisão da literatura que reúne achados de estudos desenvolvidos mediante diferentes metodologias, permitindo aos revisores sintetizar resultados sem ferir a filiação epistemológica dos estudos empíricos incluídos" ${ }^{\prime \prime}$ - e tem como intuito identificar as publicações cientificas acerca das ações de enfermagem voltadas para o público adolescente na atenção básica.

Para o desenvolvimento do estudo foram realizadas buscas na Biblioteca Virtual de Saúde (BVS), utilizando-se os descritores "adolescente", "atenção primária à saúde" e "enfermeiros" cadastrados ao DeCS (Descritores em Ciências da Saúde) e verificados com o operador booleano AND. Os critérios de inclusão estabelecidos foram artigos completos, disponíveis e publicados nos últimos seis anos (2012 a 2017), que estão disponíveis em português nas seguintes bases de dados: Literatura Latino-Americana e do Caribe em Ciências da Saúde (LILACS), Medical LiteratureAnalysisandRetrieval System Online (MEDLINE) e Base de dados de Enfermagem (BDENF). 


\section{ARTIGO ORIGINAL}

Com a associação dos descritores foram encontrados 322 artigos, que decresceram para 21 após a aplicação dos critérios de seleção supracitados, entre estes, 5 eram duplicatas, os demais foram lidos os resumos e excluídos ainda aqueles que se distanciavam do assunto ou não condiziam com o objetivo do estudo aqui abordado, totalizando 9 artigos, a Figura 1 apresenta os principais elementos do percurso metodológico. Ao final, todos foram lidos na íntegra para a sistematização e disponibilização dos resultados em um Quadro Sinóptico (Quadro 1) preenchido com informações distintas contendo título, autores, objetivo e principais resultados.

A Figura 1- Diagrama da seleção dos artigos como principais elementos do delineamentometodológico para a revisão integrativa. Guanambi - BA, 2017.

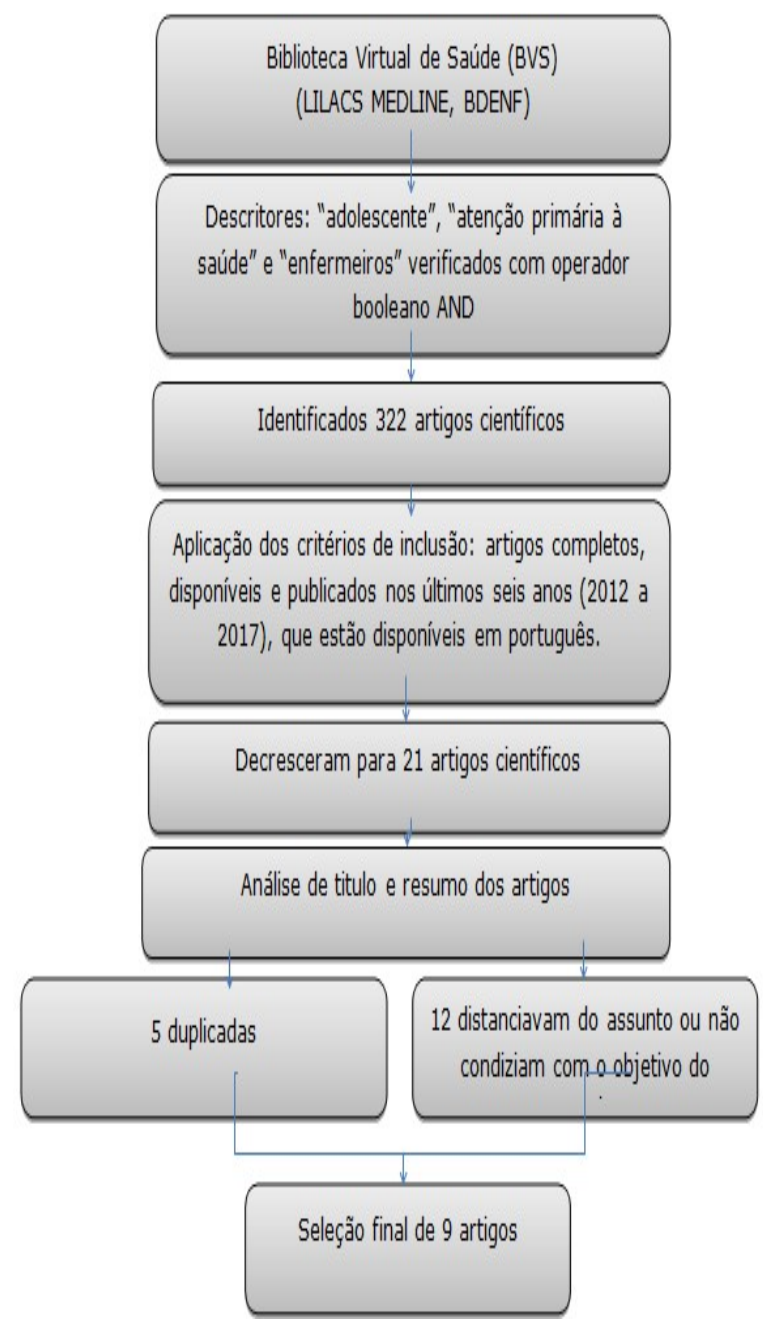

\section{RESULTADOS e DISCUSSÃO}

Para a confecção deste estudo analisaram-se 9 artigos, lidos na íntegra e que atenderam aos critérios de inclusão e ao objetivo previamente estabelecido. Dentre os artigos encontrados, não houve diferença de distribuição nas bases de dados BDENF e LILACS, com disponibilidade de 4 estudos $(44,4 \%)$ em cada um deles, e 1 estudo $(11,1 \%)$ encontra-se disponível na base de dados MEDLINE. Em relação ao ano, o maior quantitativo de publicações ocorreu no ano de 2012, com $4(44,4 \%)$ publicações, seguido de 2014 e 2016 com $2(22,2 \%)$ cada ano e 2013 com $1(11,1 \%)$.

A relação dos estudos selecionados para a construção desta revisão quanto ao título, autores, objetivo e principais resultados, encontra-se disponível no Quadro 1.

Quadro 1 - Relação dos estudos selecionados quanto ao título, autores, objetivo e principais resultados publicados entre 2012 e 2016. Guanambi BA 2017.

\begin{tabular}{|c|c|c|}
\hline $\begin{array}{c}\text { Título/Aut } \\
\text { ores }\end{array}$ & Objetivo & Principais resultados \\
\hline $\begin{array}{c}\text { Dificuldad } \\
\text { es } \\
\text { enfrentada } \\
\text { s por } \\
\text { enfermeir } \\
\text { os para } \\
\text { desenvolv } \\
\text { er ações } \\
\text { direcionad } \\
\text { as ao } \\
\text { adolescent } \\
\text { e na } \\
\text { atenção } \\
\text { primária } \\
\text { ARAújo, } \\
\text { M.S. et al. }\end{array}$ & $\begin{array}{c}\text { Identificar } \\
\text { as } \\
\text { dificuldades } \\
\text { enfrentadas } \\
\text { pelos } \\
\text { enfermeiros } \\
\text { no } \\
\text { desenvolvim } \\
\text { ento de } \\
\text { ações } \\
\text { voltadas ao } \\
\text { adolescente } \\
\text { na atenção } \\
\text { primária }\end{array}$ & $\begin{array}{c}\text { Ausência e a inadequação } \\
\text { da estrutura física e } \\
\text { sobrecarga de trabalho. }\end{array}$ \\
\hline $\begin{array}{l}\text { Acolhimen } \\
\text { to à } \\
\text { adolescent } \\
\text { e na } \\
\text { consulta } \\
\text { de } \\
\text { enfermage } \\
\text { m - estudo } \\
\text { qualitativo } \\
\text { BRASIL, }\end{array}$ & $\begin{array}{c}\text { Compreend } \\
\text { er a relação } \\
\text { do } \\
\text { enfermeiro } \\
\text { com a mãe } \\
\text { adolescente } \\
\text { na consulta } \\
\text { de } \\
\text { puericultura } \\
\text { sob o } \\
\text { enfoque do }\end{array}$ & $\begin{array}{c}\text { O acolhimento para os } \\
\text { sujeitos traz a significação } \\
\text { de escuta, receptividade e } \\
\text { inclui as formas de } \\
\text { organização do serviço que } \\
\text { envolve o enfermeiro. }\end{array}$ \\
\hline
\end{tabular}




\begin{tabular}{|c|c|c|}
\hline $\begin{array}{l}\text { E.G.M.; } \\
\text { QUEIROZ, } \\
\text { M.V.O.; } \\
\text { CUNHA, } \\
\text { J.M.H. }\end{array}$ & acolhimento & \\
\hline $\begin{array}{c}\text { A } \\
\text { adolescent } \\
\text { e grávida } \\
\text { na } \\
\text { percepção } \\
\text { de } \\
\text { médicos e } \\
\text { enfermeir } \\
\text { os da } \\
\text { atenção } \\
\text { básica } \\
\text { BUENDGE } \\
\text { NS, B.B.; } \\
\text { ZAMPIERI, } \\
\text { M.F.M. }\end{array}$ & $\begin{array}{c}\text { Conhecer a } \\
\text { percepção } \\
\text { de médicos } \\
\text { e } \\
\text { enfermeiros } \\
\text { sobre as } \\
\text { mudanças } \\
\text { biopsicossoc } \\
\text { iais da } \\
\text { adolescente } \\
\text { grávida e } \\
\text { sobre a } \\
\text { atuação da } \\
\text { equipe de } \\
\text { saúde na } \\
\text { gravidez na } \\
\text { adolescênci } \\
\text { a }\end{array}$ & $\begin{array}{l}\text { Os profissionais reforçam a } \\
\text { importância da escuta, } \\
\text { atenção personalizada, } \\
\text { integral e específica a esta } \\
\text { clientela, necessitando } \\
\text { capacitação para isto. }\end{array}$ \\
\hline $\begin{array}{c}\text { Cuidado } \\
\text { ao } \\
\text { adolescent } \\
\text { e: } \\
\text { contribuiç } \\
\text { ões para a } \\
\text { enfermage } \\
\text { m } \\
\text { COSTA, } \\
\text { R.F.; } \\
\text { QUEIROZ, } \\
\text { M.V.O.; } \\
\text { ZEITOUNE, } \\
\text { R.C.G. }\end{array}$ & $\begin{array}{c}\text { Analisar a } \\
\text { organização } \\
\text { da linha do } \\
\text { cuidado ao } \\
\text { adolescente } \\
\text { na } \\
\text { percepção } \\
\text { dos gestores } \\
\text { e dos } \\
\text { enfermeiros } \\
\text { da atenção } \\
\text { primária }\end{array}$ & $\begin{array}{l}\text { Não há planejamento para } \\
\text { este grupo populacional, } \\
\text { algumas atividades são } \\
\text { iniciativas individuais e não } \\
\text { se reportam ao } \\
\text { envolvimento dos } \\
\text { adolescentes nestas ações. }\end{array}$ \\
\hline $\begin{array}{l}\text { Cuidado } \\
\text { aos } \\
\text { adolescent } \\
\text { es na } \\
\text { atenção } \\
\text { primária: } \\
\text { perspectiv } \\
\text { as de } \\
\text { integralida } \\
\text { de } \\
\text { COSTA, } \\
\text { R.F.; } \\
\text { QUEIROZ, } \\
\text { M.V.O.; } \\
\text { ZEITOUNE, } \\
\text { R.C.G. }\end{array}$ & $\begin{array}{c}\text { Descrever } \\
\text { ações dos } \\
\text { gestores e } \\
\text { enfermeiros } \\
\text { com os } \\
\text { adolescente } \\
\text { s na atenção } \\
\text { primária, } \\
\text { baseadas } \\
\text { nas } \\
\text { perspectivas } \\
\text { da } \\
\text { integralidad } \\
\text { e }\end{array}$ & $\begin{array}{l}\text { Os sujeitos destacaram o } \\
\text { acolhimento como uma } \\
\text { ação da equipe, com } \\
\text { necessidade de } \\
\text { estabelecer vínculos e } \\
\text { motivar a reflexão dos } \\
\text { adolescentes de sua } \\
\text { responsabilidade na } \\
\text { integralidade do cuidado. }\end{array}$ \\
\hline $\begin{array}{l}\text { Desafios } \\
\text { de } \\
\text { enfermeir } \\
\text { os da } \\
\text { Estratégia } \\
\text { Saúde da }\end{array}$ & $\begin{array}{l}\text { Conhecer a } \\
\text { percepção } \\
\text { de } \\
\text { enfermeiros } \\
\text { que atuam } \\
\text { nas equipes } \\
\end{array}$ & $\begin{array}{c}\text { Construíram-se sete ideias } \\
\text { centrais: ações de atenção } \\
\text { à saúde; participação dos } \\
\text { adolescentes; } \\
\text { intersetorialidade; } \\
\text { organização estrutural e da }\end{array}$ \\
\hline
\end{tabular}

\begin{tabular}{|c|c|c|}
\hline $\begin{array}{c}\text { Família na } \\
\text { implantaçã } \\
\text { o do } \\
\text { Programa } \\
\text { Saúde do } \\
\text { Adolescent } \\
\text { e } \\
\text { DUARTE, } \\
\text { S.J.H.; } \\
\text { FERREIRA, } \\
\text { S.F.; } \\
\text { SANTOS, } \\
\text { N.C. }\end{array}$ & $\begin{array}{l}\text { em que se } \\
\text { têm } \\
\text { implantado } \\
\text { o Projeto de } \\
\text { Educação } \\
\text { pelo } \\
\text { Trabalho na } \\
\text { área da } \\
\text { Saúde da } \\
\text { Família, } \\
\text { quanto às } \\
\text { ações } \\
\text { desenvolvid } \\
\text { as no } \\
\text { Programa } \\
\text { Saúde do } \\
\text { Adolescente }\end{array}$ & $\begin{array}{l}\text { assistência ao adolescente; } \\
\text { multidisciplinaridade e } \\
\text { interdisciplinaridade; } \\
\text { necessidade de } \\
\text { capacitação sobre } \\
\text { adolescência. }\end{array}$ \\
\hline $\begin{array}{l}\text { Enfrentam } \\
\text { ento da } \\
\text { violência } \\
\text { doméstica } \\
\text { contra } \\
\text { crianças e } \\
\text { adolescent } \\
\text { es na } \\
\text { perspectiv } \\
\text { a de } \\
\text { enfermeir } \\
\text { os da } \\
\text { atenção } \\
\text { básica } \\
\text { LEITE, T.J. } \\
\text { et al. }\end{array}$ & $\begin{array}{c}\text { Analisar as } \\
\text { ações } \\
\text { relatadas } \\
\text { por } \\
\text { enfermeiros } \\
\text { da atenção } \\
\text { básica no } \\
\text { enfrentame } \\
\text { nto da } \\
\text { violência } \\
\text { doméstica } \\
\text { contra } \\
\text { crianças } \\
\text { e } \\
\text { adolescente } \\
\text { s }\end{array}$ & $\begin{array}{l}\text { As enfermeiras conheciam } \\
\text { as políticas públicas, mas } \\
\text { não conseguiam colocá-las } \\
\text { em prática; estavam } \\
\text { despreparadas para } \\
\text { identificar e enfrentar a } \\
\text { violência; não } \\
\text { participavam de cursos de } \\
\text { capacitação; temiam } \\
\text { notificar os casos } \\
\text { detectados de violência. }\end{array}$ \\
\hline $\begin{array}{c}\text { Fatores } \\
\text { associados } \\
\text { à } \\
\text { notificação } \\
\text { de maus- } \\
\text { tratos em } \\
\text { crianças e } \\
\text { adolescent } \\
\text { es na } \\
\text { atenção } \\
\text { básica } \\
\text { MOREIRA, } \\
\text { G.A.R. et } \\
\text { al. }\end{array}$ & $\begin{array}{l}\text { Analisar os } \\
\text { fatores } \\
\text { associados à } \\
\text { notificação } \\
\text { de maus- } \\
\text { tratos em } \\
\text { crianças e } \\
\text { adolescente } \\
\text { s na atenção } \\
\text { básica }\end{array}$ & $\begin{array}{l}\text { A frequência da notificação } \\
\text { de maus-tratos pelos } \\
\text { profissionais da atenção } \\
\text { básica foi de } 17,0 \% \text {. } \\
\text { Participar de treinamento } \\
\text { sobre o tema, conhecer a } \\
\text { ficha de notificação e } \\
\text { saber encaminhar os casos } \\
\text { aumentou a chance dos } \\
\text { profissionais notificarem } \\
\text { situações de maus-tratos } \\
\text { em crianças e } \\
\text { adolescentes. }\end{array}$ \\
\hline $\begin{array}{l}\text { Atuação } \\
\text { dos } \\
\text { enfermeir } \\
\text { os de } \\
\text { Unidades } \\
\text { Básicas de } \\
\text { Saúde } \\
\text { direcionad } \\
\text { a aos } \\
\text { adolescent } \\
\text { es com } \\
\end{array}$ & $\begin{array}{l}\text { Identificar a } \\
\text { percepção } \\
\text { dos } \\
\text { enfermeiros } \\
\text { das } \\
\text { Unidades } \\
\text { Básicas de } \\
\text { Saúde sobre } \\
\text { sua atuação } \\
\text { na avaliação } \\
\text { para } \\
\end{array}$ & $\begin{array}{c}\text { Dificuldade no } \\
\text { acompanhamento do } \\
\text { adolescente na Atenção } \\
\text { Primária } \\
\text { em Saúde; causas do } \\
\text { crescimento do excesso de } \\
\text { peso na adolescência; } \\
\text { ações de saúde nas } \\
\text { escolas; e } \\
\text { prevenção/identificação/in } \\
\text { tervenção }\end{array}$ \\
\hline
\end{tabular}




\section{ARTIGO ORIGINAL}

\begin{tabular}{|c|c|c|}
\hline $\begin{array}{c}\text { excesso de } \\
\text { peso nas } \\
\text { escolas }\end{array}$ & $\begin{array}{c}\text { excesso de } \\
\text { peso em } \\
\text { adolescente } \\
\text { s nas } \\
\text { VIEIRA, }\end{array}$ & $\begin{array}{c}\text { no excesso de peso em } \\
\text { adolescentes nas escolas. }\end{array}$ \\
$\begin{array}{c}\text { C.E.N.K. et } \\
\text { al. }\end{array}$ & & \\
\hline
\end{tabular}

Após a análise dos resultados, verificouse que os estudos selecionados, em sua maioria trazem ações de assistência gerais da atenção básica que podem ser aplicadas ao adolescente, no entanto, atividades desenvolvidas especificamente para esse grupo populacional foram pouco descritas. Desse modo, em resposta ao objetivo proposto, emergiram duas categorias temáticas, a saber, "Ações de enfermagem direcionada ao adolescente na atenção primária" e "Dificuldades encontradas pelos profissionais de enfermagem na atenção integral ao adolescente na atenção primária".

\section{Ações de enfermagem direcionada ao adolescente na atenção primária}

Aassiduidade de adolescentes na atenção primária é uma necessidade, visto que estes encontram-se em situação de vulnerabilidade devido sua exposição a infecções sexualmente transmissiveis, gravidez não planejada, violência e uso de álcool e/ou drogas, no entanto, mesmo após o lançamento das "Diretrizes Nacionais para a Atenção Integral à Saúde de Adolescentes e de Jovens na Promoção, Proteção e Recuperação da Saúde" pelo Ministério da Saúde em 2010, é sabido que este público ainda é o menos atraído aos serviços de saúde oferecidos á população. ${ }^{7,4}$

É indispensável que os profissionais estejam articulados no desenvolvimento de estratégias apropriadas às complexidades das demandas do adolescente, pois mesmo que o estabelecimento das diretrizes para conduzir os cuidados voltados para este grupo sejam recentes, a equipe engajada na assistência precisa tomar a iniciativa de atualizar conhecimentos e desenvolver práticas que coincidam com a política em vigência, ou seja, buscar meios para garantir a atenção integral, resolutiva e participativa ao indivíduo nesta fase da vida. ${ }^{8}$

Entre as condutas voltadas para o público adolescente, apesenta-se como uma das ações de enfermagem, o Programa Saúde na Escola (PSE), que se trata de um programa estratégico que objetiva unir dois espaços inerentes ao desenvolvimento do indivíduo nesse período de transição, a atenção primária e a escola. ${ }^{4}$ O PSE traz ainda, orientações sobre promoção e proteção à saúde o que tem alcançado jovens com mais facilidade, além de propiciar uma maior procura destes aos profissionais de saúde. ${ }^{9}$

Outra ação fortemente relatada como método de assistência aos jovens é o acolhimento que geralmente reflete a escuta sensível do indivíduo, na busca de compreender sua necessidade e intervir assegurando-Ihe uma resolutividade, além de favorecer aumento da autonomia e confiança. $O$ autor ainda discute que acolhimento confere a inclusão do jovem à unidade de saúde e deve ser cultivada ainda na recepção a partir de condutas que demonstrem atenção e respeito, assim, ao construir uma boa impressão do ambiente e dos profissionais envolvidos nesse acolhimento, há maior probabilidade de formação de vínculo com o serviço. ${ }^{1}$

Em contrapartida, outros estudos revelam as perspectivas da integralidade em relação aos cuidados aos adolescentes na atenção básica, que as ações de acolhimento não devem ser consideradas como uma ação de atenção à saúde do adolescente, pois tratase de uma atividade não institucionalizada e dispensada ao público em geral e não especificamente a esta categoria. Este estudo ainda afirma a importância de ações que favoreçam a autonomia do usuário e sua corresponsabilização no cuidado, no entanto, sabe-se que são necessárias atividades concretas capazes de atrair o jovem ao serviço e despertar nele essas atribuições, bem como cativar o interesse de participar continuamente das atividades de prevenção, promoção e proteção da saúde. ${ }^{10}$

A atenção ao adolescente quando este encontra-se inserido em outros serviços, como 


\section{ARTIGO ORIGINAL}

por exemplo, consulta pré-natal. A assistência à adolescente em situação de gravidez é um desafio para os profissionais, pois há o enfrentamento de uma transição inesperada de papéis, de adolescente à mulher, que acomoda alterações biopsicossociais, resultando em crise e sofrimento, diante disso, o autor sugere que a assistência deve conferir um olhar sensível e personalizado que permita compreender a nova vivência experimentada por esta jovem, evidenciando o acolhimento como conduta. ${ }^{7}$

Outra ação citada na atenção ao público jovem foi a promoção do fácil acesso do adolescente aos serviços de saúde e o fortalecimento de vínculo, bem como a utilização dos serviços de referência e contrareferência utilizados no intuito de garantir a atenção integral ao usuário, no entanto, estas ações revelam-se mais uma vez na escuta, não revelando medidas pensadas segundo as especificidades deste grupo. ${ }^{10,7}$ Além do mais, o serviço de referência e contra-referência precisa estar inter-relacionado a ações específicas para propiciar maior resolutividade, pois verifica-se em um estudo sobre violência doméstica contra crianças e adolescentes, a dificuldade dos profissionais em identificar e interagir em casos de violência, bem como acompanhar o desfecho quando este é notificado e referenciado a autoridades competentes. ${ }^{11,12}$

O Programa Saúde do Adolescente (PROSAD), que devido o alcance satisfatório de suas ações, em 1989 foi oficializado pelo Ministério da Saúde como política da área da saúde com a fim de promover ações programadas voltadas ao adolescente com o objetivo de propiciar e integrar práticas de assistência à saúde a partir da identificação precoce de agravos e grupos de risco, bem como possibilitar a reabilitação da saúde, desse modo, considerando a complexidade das atividades que abrangem o atendimento integral de um adolescente, este programa apoia-se na intersetorialidade e inter/multidisciplinaridade para desenvolver suas atividades. ${ }^{13}$

\section{Dificuldades encontradas pelos profissionais de enfermagem na atenção integral ao adolescente na atenção primária}

Em meio às ações desenvolvidas pelos enfermeiros na atenção básica para atender o público adolescente, algumas dificuldades são levantadas, apresentando-se como entraves que dificultam o atendimento e acompanhamento desse grupo. Nessa perspectiva, a maior parte dos estudos analisados descreve porque muitas ações não são realizadas ou executadas como se devem, objetivando acolher e atender esses adolescentes. 4,13,8,11,12,9

Uma das barreiras encontradas diz respeito à estrutura física da unidade básica de saúde, que é pouco atrativa para os adolescentes, desmotivando sua procura. Ou mesmo a falta de espaço e locais que inviabilizam o desenvolvendo de atividades de caráter educativos, sendo a estrutura da unidade um elemento significativo para o acolhimento dos usuários adolescentes. ${ }^{4}$

O espaço físico inapropriado para desenvolvimento de atividades, a indisponibilidade de tempo e agenda lotada dos profissionais, dificulta o acesso desse grupo aos serviços de saúde. É evidenciado ainda, a necessidade de organizar a estrutura e dinâmica da unidade o que beneficiaria seu acesso, agendar períodos para desenvolver atividades assistências e educativas, visitas domiciliares, oficinas em grupo, criar ou modificar ambientes para que os mesmos se sintam mais confortáveis e acolhidos. ${ }^{13}$

A demanda de trabalho dos enfermeiros na atenção primária de saúde é vista como um obstáculo para desenvolver ações voltadas para o público jovem. Essa sobrecarga de trabalho enfraquece a promoção da saúde, uma vez que o enfermeiro tem muitas demandas a serem cumpridas restando pouco tempo para as ações com a população, principalmente os adolescentes. ${ }^{4}$

Esse achado corrobora com outros estudosque expõe a sobrecarga de trabalho descrita pelos enfermeiros entrevistados como empecilho para a realização de atividades para os adolescente, esse fato é 


\section{ARTIGO ORIGINAL}

explicado por não ser obrigatório atender adolescentes e por não se ter um programa especifico para o atendimento do mesmo, priorizando a população com doenças crônicas, como o programa hiperdia, preventivos, puericultura, visitas domiciliares entre outros. ${ }^{14}$

A falta de interatividade no trabalho coletivo bem como o desinteresse de alguns profissionais que compõem a equipe multidisciplinar é outro problema, pois levam a fragilidade e fragmentação do atendimento da clínica e do planejamento da assistência para os adolescentes, uma vez que, alguns enfermeiros realizam ações de forma isolada ao invés de planejadas e executadas em equipe. A ausência dessas ações impossibilita uma atenção integral ao jovem, já que ações isoladas não são resolutivas, por isso há necessidade de trabalhar em equipe elencando todas as suas demandas, para elaboração de um planejamento em saúde. ${ }^{10}$

Os enfermeiros no seu processo de trabalho enfrentam dificuldades para realizar notificações, pois além de sentir-se desamparados existe $o$ receito de envolvimento legal. A enfermagem muitas das vezes tem o conhecimento da ocorrência de agressões físicas, porém acabam omitindo-se do processo judicial, pelo medo de retaliação por parte do autor da agressão, pela ausência de um programa de suporte e proteção. ${ }^{11}$

O estudo corrobora com o exposto, acrescentando que a enfermagem não está apta para lidar com a agressão doméstica de maneira efetiva, por falta de capacitação, e ressalta ainda a necessidade de a Secretaria de Saúde criar ações que envolvam os enfermeiros em atividades para sua capacitação, para quando ocorrer atos de agressões os mesmos saberem as medidas cabíveis. ${ }^{12}$

A postura dos profissionais diante a uma adolescente grávida, os quais relatam que $a$ atenção prestada a jovem grávida é bem próximo a de qualquer outra gestante, desconsiderando a necessidade de um enfoque na saúde mental, emocional, esclarecimento de dúvidas, medos e seus direitos. $^{7}$
A ausência de capacitação dos profissionais no que diz respeito à abordagem e desempenho de atividade juntos aos jovens, se constrói como grande barreira já que o enfermeiro por estar despreparado, muitas das vezes, pode não saber lidar com a situação. Os mesmos reconhecem a importância de uma preparação profissional, uma educação continuada, bem como a disponibilidade de recursos materiais e didáticos, capazes de atrair a atenção dos adolescentes. ${ }^{15}$

Em decorrência das dificuldades apresentadas, para que exista uma assistência de enfermagem eficiente e eficaz ao adolescente na atenção primária são necessárias algumas mudanças. Partindo prioritariamente da reorganização de programas existentes que não englobam 0 público adolescente. A efetivação de políticaspúblicas para ampliar o acesso dos mesmos, seria o ponta pé para mudanças, pois na existência de um programa especifico, os adolescentes sentiriam se estimulados a comparecer ao serviço. Os profissionais por sua vez, com tempo reservado para os adolescentes elaborariam e executariam atividades assistências e educativas, individuais e em grupo no intuito de fortalecer o vínculo e atender suas necessidades.

\section{CONCLUSÃO}

Em suma, nota-se que as ações de enfermagem voltadas ao público adolescente na atenção básica são pautadas basicamente em orientações - atreladas a outros setores como a educação, através do Programa Saúde na Escola - e na busca pelo fortalecimento de vínculo e acolhimento adequado, além daquelas que já tratam o adolescente em situação de agravo.

Essa realidade ressaltada principalmente a ausência do adolescente na procura pelo serviço, devido à fragilidade de vínculo entre profissionais de saúde e o adolescente, o que dificultada a manutenção de ações efetivas e a atenção integral nesse âmbito. Além desta, aponta-se como dificuldades ainda, a falta de estrutura física 


\section{ARTIGO ORIGINAL}

adequada, o despreparo dos profissionais e a demanda dos serviços a outros públicos que prejudicam a articulação de ações regulares.

Sendo assim, percebe-se que a atenção a este público se revela inconsistente e insatisfatório para as suas necessidades de saúde no que concerne aos conceitos de prevenção e promoção pois, pauta-se em ações pontuais e muitas vezes que não proporcionam continuidade ao cuidado prestado.

O uso da revisão interativa como metodologia para o presente estudo mostrousevalido para o alcance do objetivo e para apontar lacunas existentes que expõem as necessidades que devem ser revistas e trabalhadas. Faz necessário ainda, que novos estudos sejam realizados para a ampliação das discussões a respeito da temática, e para a consolidação de estratégias mais solidas que beneficie esse público.

\section{REFERÊNCIAS}

1. Brasil EGM, Queiroz MVO, Cunha JMH. Acolhimento à adolescente na consulta de enfermagem - estudo qualitativo. Online braz j nurs, [Internet]. 2012 [acesso em: 24 mai 2017]; 11 (2); 346-58. Disponível em:

http://www.objnursing.uff.br/index.php/nursi ng/article/view/3752

2. Tatmatsu DB, Araújo ACC. Atenção primária e saúde mental: contribuições e potencialidades do apoio matricial. Mudanças - Psicologia da Saúde [Internet]. 2016 [acesso em 01 abr 2017];24 (2) 71-79. Disponível em: https://www.metodista.br/revistas/revistasims/index.php/MUD/article/viewFile/6720/55 42

3. Rehem TCMSB, Egry EY, Ciosak SI, Santos WS. Quais aspectos contribuem para a ocorrência de internações por condições sensíveis à atenção primária? Rev. Bras. Promoç. Saúde. Fortaleza, [Internet]. 2016 [acesso em 20 mai 2017]; 29 138147.Disponível em:
http://periodicos.unifor.br/RBPS/article/view/ 6415

4. Araújo MS, Sales LKO, Araújo MG, Morais IF, Morais FRR, Valença CN. Dificuldades enfrentadas por enfermeiros para desenvolver ações direcionadas ao adolescente na atenção primária. Revenferm UFPEonline [internet]. 2016 [acesso em 13 abr 2017];10(5);4219-25. Disponível em: https://periodicos.ufpe.br/revistas/revistaenf ermagem/article/view/11166

5.Brasil DF. Secretaria de Estado de Saúde. Comissão Permanente de Protocolos de Atenção à Saúde. Brasília, DF; Distrito Federal. (Brasil). Secretaria de Estado de Saúde. Comissão Permanente de Protocolos de Atenção à Saúde; 6 dez. 2016.

6. Soares CB, Hoga LAK, Peduzzi M, Sangaleti $C$, Yonekura T, Silva DRAD. Revisão integrativa: conceitos e métodos utilizados na enfermagem. Rev. esc. enferm. USP, [Internet]. 2014 [acesso em: 28 mai 2017]; 48 (2); 335-45. Disponível:

http://www.redalyc.org/html/3610/36103333 6020/

\section{Buendgens BB, Zampieri MFM. A}

Adolescente grávida na percepção de médicos e enfermeiros da atenção básica. Esc Anna Nery (impr.). [Internet]. 2012 [acesso em 12 abr 2017]; 16 (1); 64-72. Disponível em: http://www.redalyc.org/pdf/1277/127721430 009.pdf

8. Costa RF, Queiroz MVO, Zeitoune RCG. Cuidado ao adolescente: contribuições para a enfermagem. Rev. enferm. UERJ, [Internet]. 2012 [acesso em: 25 mai 2017]; 20(2); 197202. Disponível em: http://www.epublicacoes_teste.uerj.br/index.php/enferma gemuerj/article/view/4045

\section{Vieira CENK, Enders BC, Mariz LS, Santos} RJF, Rêgo MCD, Oliveira DRC. Atuação dos enfermeiros de Unidades Básicas De Saúde direcionada aos adolescentes com excesso de Peso nas escolas. Rev Min Enferm., [Internet]. 


\section{ARTIGO ORIGINAL}

2014 [acesso em 20 mai 2017]; 18 (3); 630 636. Disponível em:

http://www.reme.org.br/artigo/detalhes/951

10. Costa RF, QueirozMVO, Zeitoune RCG. Cuidado aos adolescentes na atenção primária: perspectivas de integralidade. Esc Anna Nery (impr.), [Internet]. 2012 [acesso em 13 mai 2017]; 16 (3); 466-472. Disponível em: http://www.redalyc.org/pdf/1277/127723305 006.pdf

11. Moreira GAR, Vieira LJES, Deslandes SF, Maria AJP, Gama IS, Brilhante AV. Fatores associados à notificação de maus-tratos em crianças e adolescentes na atenção básica. Ciência \& Saúde Coletiva, [Internet]. 2014 [acesso em: 25 mai 2017];19 (10); 4267-76. Disponível em:

http://www.redalyc.org/html/630/630321140 31/

12. Leite JT, Beserra MA, Scatenaa L, Silva LMP, Ferrian MG. Enfrentamento da violência doméstica contra crianças e adolescentes na perspectiva de enfermeiros da atenção básica. Rev Gaúcha Enferm., [Internet]. 2016 [acesso em: 24 mai 2017]; 37 (2); 55796 1. Disponível em:

www.seer.ufrgs.br/revistagauchadeenfermag em

13. Duarte SJH, Ferreira SF, Santos NC. Desafios de enfermeiros da Estratégia Saúde da Família na implantação do Programa Saúde do Adolescente. Rev. Eletr. Enf., [Internet]. 2013 [acesso em 05 abr 2017];15 (2); 479-86. Disponível em:

http://dx.doi.org/10.5216/ree.v15i2.18179.

14. Henriques BD, Rocha RL, Madeira AMF. Saúde do adolescente: o significado do atendimento para os profissionais da atenção primária do município de Viçosa. Rev. Med., [Internet]. 2010 [acesso em 23 mai 2017];20(3); 300-309. Disponível em: http://pesquisa.bvs.br/brasil/resource/pt/lil564334
15. Higarashi IH, Baratieri T, Roecker S, Marcon SS. Atuação do enfermeiro junto aos adolescentes: identificando dificuldades e perspectivas de transformação. Rev. enferm. UERJ, [Internet]. 2011 [acesso em 17 mai 2017]; 19 (3);375-80. Disponível em: http://pesquisa.bvs.br/brasil/resource/pt/lil618859 